\title{
Character lability in deep-sea bamboo corals (Octocorallia, Isididae, Keratoisidinae)
}

\author{
Luisa F. Dueñas, Juan A. Sánchez* \\ Departamento de Ciencias Biológicas-Facultad de Ciencias, Laboratorio de Biología Molecular Marina (BIOMMAR), \\ Universidad de los Andes, Carrera 1 \#18A-10, Bogotá, Colombia
}

\begin{abstract}
Morphological traits that appear multiple times when mapped onto molecular phylogenies have been associated with character lability. In an ecological context, functional characters, if labile, could confer advantages for adaptation to specific habitats. Bamboo corals are long-lived, deep-sea octocorals characterized by an obvious modularity, which affords diverse branching morphologies in the Keratoisidinae subfamily. We reconstructed molecular phylogenies using 16S (mitochondrial) and ITS2 (nuclear) ribosomal DNA, and obtained 39 ITS2 and 2216 Sequences from 22 different specimens. The molecular topologies showed Keratoisidinae genera as polyphyletic. Twelve morphological characters were chosen to make the ancestral character reconstruction, none of which exhibited character states forming monophyletic groups when mapped onto molecular phylogenies. The different character states appeared as having been gained and lost multiple times. Modular organisms such as bamboo corals could have higher character evolvability than unitary organisms. Complexity arising from simple body plans is a typical characteristic in most modular organisms, such as plants and colonial marine invertebrates. However, bamboo corals may also exhibit phenotypic plasticity associated with continuous characters, given that they can respond to extrinsic controls. Our results also have direct repercussions on Isididae taxonomy, since morphological characters have been used for their classification. Consequently, we suggest that the current taxonomy of the group is re-evaluated and that the different mechanisms regulating modularity and character evolution in bamboo corals are explored.
\end{abstract}

KEY WORDS: Character lability · Isididae - Bamboo corals · Ancestral character state reconstruction · Keratoisidinae $\cdot$ New Zealand $\cdot$ Deep-sea corals

Resale or republication not permitted without written consent of the publisher

\section{INTRODUCTION}

Our understanding of biological diversity has relied for a long time on morphological characters to reveal relationships among species. It has been expected that with the implementation of molecular phylogenetic techniques our appreciation of morphological characters would improve. Subsequently, synapomorphies used in taxonomic classifications turned into testable hypotheses for molecular phylogenies, where congruence between morphological and molecular topologies was expected. Correspondence between morphological and molecular hypotheses has been observed (e.g. Bousquet et al. 1992), but often incongruence has been encountered (e.g. Geisler 2001, Masters \& Broth- ers 2002, Jousselin et al. 2004, Draper et al. 2007). Although incongruence between morphological and molecular results was initially considered a negative homoplasious result, it has actually opened a new window in terms of understanding the evolution of morphological characters. In particular, morphological characters that appear multiple times when mapped onto molecular phylogenies have been associated with character lability (Jousselin et al. 2004, Kimball \& Crawford 2004).

Silvertown et al. (2006) defined evolutive labile characters as heritable traits that can vary freely among the tips of a given phylogeny. This definition was proposed for an ecological context where niche-associated characters (or functional characters), if labile, could confer 
advantages for adaptation in a specific habitat (Emerson \& Gillespie 2008). In this case, specific abiotic conditions and competitive interactions generate selective pressures that define the trait similarities that cooccurring species will share (Swenson et al. 2007, Emerson \& Gillespie 2008). All these interactions create the phylogenetic structuring observed in natural environments (Silvertown et al. 2006). Although Silvertown et al. (2006) defined trait lability in an ecological context, their argument can be applied in a taxonomical context with non-functional characters used for the identification and classification of species. Character lability in a taxonomical context has usually been associated with character homoplasy as either putative convergence or parallelism (Kimball \& Crawford 2004). It can also be linked to character reacquisition violating Dollo's Law (Collin \& Miglietta 2008), where complex characters that have been lost cannot be reacquired. Reverse evolution, defined as the derived reacquisition of ancestral character states (Porter \& Crandall 2003), can also explain the same phenomenon.

Morphological character lability is rather common in nature. Trait lability has been reported in a number of land organisms such as plants (Kimball \& Crawford 2004, Ogburn \& Edwards 2009), mosses (Shaw \& Allen 2000), mammals (Sánchez-Villagra \& Williams 1998), wasps (Jousselin et al. 2004) and amphibians (e.g. salamanders, Chippindale et al. 2004, Mueller et al. 2004). Character lability has also been documented in marine organisms such as gastropods (Collin \& Cipriani 2003, Collin et al. 2007), sponges (Borchiellini et al. 2004) and shallow-water octocorals (Sánchez 2004). Given the pattern of character lability shown by Sánchez (2004) in shallow-water octocorals, it is reasonable to expect a similar outcome in deep-sea octocorals such as bamboo corals.

Bamboo corals are long-lived, deep-sea octocorals that have arborescent or whip-like growth patterns (Noé \& Dullo 2006). These conspicuous octocorals have characteristic white calcareous internodes and dark proteinaceous nodes (Grant 1976), are widely distributed on seamounts (Sánchez \& Rowden 2006) and are particularly abundant from 200 to $1500 \mathrm{~m}$ water depth (Etnoyer et al. 2006). Although bamboo corals are common deep-sea inhabitants, their phylogenetic relationships have just recently been explored in the subfamily Keratoisidinae (Isididae). Current findings suggest that characters normally used for taxonomic classification (e.g. branching pattern, branching plane, polyp length) in isidids are actually not reliable (France 2007). Owing to the broad range of variation in isidid traits (L. F. Dueñas \& J. A. Sánchez unpubl. data), we propose here that most of these traits evolved independently multiple times. In the present study, we asked whether morphological characters in bamboo corals
(Keratoisidinae) are labile or not, using New Zealand fauna as a model. We used 16S mtDNA and ITS nDNA sequences to explore (1) Keratoisidid phylogenetic relationships and (2) character lability in bamboo corals.

\section{MATERIALS AND METHODS}

Sample collection. Dry and 96\% ethanol-preserved coral tissues were available from the National Institute of Water and Atmospheric Research (NIWA) Invertebrate Collection in Wellington, New Zealand, and from the National Museum of Natural History (USNM) Smithsonian Institution. Samples from NIWA (18 samples) were collected in a series of expeditions around New Zealand and the Antarctic region, and samples from USNM ( 3 samples) were collected in the US in the North Pacific and Atlantic Oceans.

The Keratoisidinae subfamily comprises 5 genera according to Bayer (1990): Isidella Gray, 1857; Keratoisis Wright, 1869; Acanella Gray, 1870; Lepidisis Verrill, 1883; and Orstomisis Bayer, 1990. There are at least 54 species described within this subfamily. We obtained samples from 4 of the 5 Keratoisidinae genera: Isidella (2 samples, 1 species), Keratoisis (16 samples, 3 described species and 10 morpho-species), Acanella (2 samples, 1 described species and 1 morphospecies), and Lepidisis (1 sample, 1 species); and 2 outgroup taxa (Narella nuttingi and Calyptrophora japonica: Primnoidae). Identifications and GenBank accession numbers are listed in Table 1.

All specimens were analyzed for macroscopic and microscopic features for proper identification. Macroscopic features were defined as those describing the overall structure of the colonies such as (I) internode texture, (II) internode length, (III) internode width, (IV) internode/ node length proportion, (V) branching, (VI) branching plane, (VII) colony appearance, (VIII) polyp length, (IX) polyp shape, (X) polyp sclerite (needle) length, (XI) polyp sclerite (needle) width and (XII) polyp sclerite texture (Table 2, Fig. 1). Microscopic features were explored using scanning electron microscopy (SEM) and comprised sclerite morphology and arrangement (Table 2, Fig. 1). A great effort was made to identify all the samples to the lowest level possible, but most species, because of the low quality of the material, could not be identified, so morphospecies were defined based on the characters mentioned above.

DNA extraction, amplification and sequencing. DNA was extracted from both dry samples and $96 \%$ ethanol-preserved tissue following a cetyl trimethylammonium bromide (CTAB) protocol (Coffroth et al. 1992). Extracted DNA was resuspended in tris-ethylenediaminetetraacetic acid (TE) buffer $(30 \mu \mathrm{l})$, and then diluted (1:50 and 1:20) for PCR use. 16S mtDNA 
Table 1. Specimen information for the octocoral samples analyzed. NIWA: National Institute of Water and Atmospheric Research, Wellington, New Zealand; USNM: National Museum of Natural History Smithsonian Institution, Washington, DC

\begin{tabular}{|c|c|c|c|c|}
\hline Specimen no. & Identification & $\begin{array}{c}\text { 16S GenBank accession } \\
\text { no. }\end{array}$ & $\begin{array}{l}\text { ITS2 copy } \\
\text { identification }\end{array}$ & $\begin{array}{c}\text { ITS2 GenBank accession } \\
\text { no. }\end{array}$ \\
\hline NIWA14350 & Lepidisis solitaria & FJ790887 & $\begin{array}{l}\text { L14350A } \\
\text { L14350B } \\
\text { L14350C } \\
\text { L14350D }\end{array}$ & $\begin{array}{l}\text { FJ790908 } \\
\text { FJ790909 } \\
\text { FJ790910 } \\
\text { FJ790911 }\end{array}$ \\
\hline NIWA14357 & Keratoisis sp.9 & FJ790888 & $\begin{array}{l}\text { K14357A } \\
\text { K14357C }\end{array}$ & $\begin{array}{l}\text { FJ790912 } \\
\text { FJ790913 }\end{array}$ \\
\hline NIWA14359 & Keratoisis sp.14 & FJ790889 & $\begin{array}{l}\text { K14359A } \\
\text { K14359B } \\
\text { K14359C } \\
\text { K14359D } \\
\text { K14359E } \\
\text { K14359F } \\
\text { K14359G }\end{array}$ & $\begin{array}{l}\text { FJ790914 } \\
\text { FJ790915 } \\
\text { FJ790916 } \\
\text { FJ790917 } \\
\text { FJ790918 } \\
\text { FJ790919 } \\
\text { FJ790920 }\end{array}$ \\
\hline NIWA14373 & Acanella sp.2 & FJ790890 & $\begin{array}{l}\text { A14373A } \\
\text { A14373B }\end{array}$ & $\begin{array}{l}\text { FJ790921 } \\
\text { FJ790922 }\end{array}$ \\
\hline NIWA14375 & Keratoisis n. sp.1 & FJ790891 & $\mathrm{K} 14375 \mathrm{~A}$ & FJ790923 \\
\hline NIWA15647 & Keratoisis sp.6 & FJ790892 & $\begin{array}{l}\text { K15647A } \\
\text { K15647B } \\
\text { K15647C }\end{array}$ & $\begin{array}{l}\text { FJ790924 } \\
\text { FJ790925 } \\
\text { FJ790926 }\end{array}$ \\
\hline NIWA15649 & Keratoisis sp.17 & FJ790893 & $\begin{array}{l}\text { K15649A } \\
\text { K15649B }\end{array}$ & $\begin{array}{l}\text { FJ790927 } \\
\text { FJ790928 }\end{array}$ \\
\hline NIWA26580 & Keratoisis sp.16 & FJ790894 & K26580A & FJ790929 \\
\hline NIWA26586 & Keratoisis sp.10 & FJ790895 & K26586B & FJ790930 \\
\hline NIWA26591 & Keratoisis sp.16 & FJ790896 & $\begin{array}{l}\text { K26591A } \\
\text { K26591B } \\
\text { K26591C }\end{array}$ & $\begin{array}{l}\text { FJ790931 } \\
\text { FJ790932 } \\
\text { FJ790933 }\end{array}$ \\
\hline NIWA26593 & Keratoisis sp.16 & FJ790897 & K26593A & FJ790934 \\
\hline NIWA26596 & Keratoisis sp.8 & FJ790898 & K26596A & FJ790935 \\
\hline NIWA26597 & Keratoisis sp.9 & FJ790899 & $\begin{array}{l}\text { K26597A } \\
\text { K26597B }\end{array}$ & $\begin{array}{l}\text { FJ790936 } \\
\text { FJ790937 }\end{array}$ \\
\hline NIWA26600 & Keratoisis sp.15 & FJ790900 & $\mathrm{K} 26600 \mathrm{~A}$ & FJ790938 \\
\hline NIWA26602 & Keratoisis zelandica & FJ790901 & K26602A & FJ790939 \\
\hline NIWA28048 & Keratoisis sp.7 & FJ790902 & K28048B & FJ790940 \\
\hline H124-NIWA1759 & Keratoisis hikurangiensis & FJ790903 & H124A & FJ790941 \\
\hline H125-NIWA1814 & Keratoisis projecta & FJ790904 & H125B & FJ790942 \\
\hline USNM1072291 & Acanella weberi & FJ790905 & S1072291A & FJ790943 \\
\hline USNM1076658 & Isidella tentaculum & FJ790906 & S1076658A & FJ790944 \\
\hline USNM1082175 & $\begin{array}{l}\text { Isidella tentaculum } \\
\text { Narella nuttingi } \\
\text { Calyptrophora japonica }\end{array}$ & $\begin{array}{l}\text { FJ790907 } \\
\text { U20307 }\end{array}$ & S1082175A & $\begin{array}{l}\text { FJ790945 } \\
\text { EF090735 }\end{array}$ \\
\hline
\end{tabular}

sequences were obtained using primers designed by France et al. (1996). The following PCR profile was used: 0.5 units of Taq polymerase (Go Taq Pomega), $3.0 \mathrm{mM} \mathrm{MgCl}, 10 \mu \mathrm{M}$ primer (forward and reverse), $10 \mathrm{mM}$ deoxyribonucleotide triphosphate (dNTPs) and $2 \mu \mathrm{l}$ of the dilution $1: 50$ or $1: 20$. The PCR conditions were $2 \mathrm{~min}$ at $94^{\circ} \mathrm{C}, 1 \mathrm{~min}$ at $94^{\circ} \mathrm{C}, 1 \mathrm{~min}$ at $55^{\circ} \mathrm{C}$ and $1.5 \mathrm{~min}$ at $72^{\circ} \mathrm{C}$ for 35 cycles. PCR product presequencing purification was carried out using an Exosap kit (Fermentas), and sequencing was done using BigDye TM Terminator v3.1 (Applied Biosystems). The samples were sequenced in a capillary electrophoresis automated sequencer (ABI 310, Applied Biosystems). Consensus sequences (sequencing from both directions) were obtained automatically by assembling the 2 complementary DNA chromatograms using Geneious software (Biomatters).

Internal transcribed spacer 2 (ITS2) sequences were obtained using the PCR profile and primers designed by Aguilar \& Sánchez (2007). PCR products were run in a denaturing gradient ( 45 to $80 \%$ ) polyacrylamide gel under an electrophoresis DGGE at $90 \mathrm{~V}$ and $60^{\circ} \mathrm{C}$ for $14 \mathrm{~h}$. Gels were stained with ethidium bromide and all visualized bands were excised and reamplified 


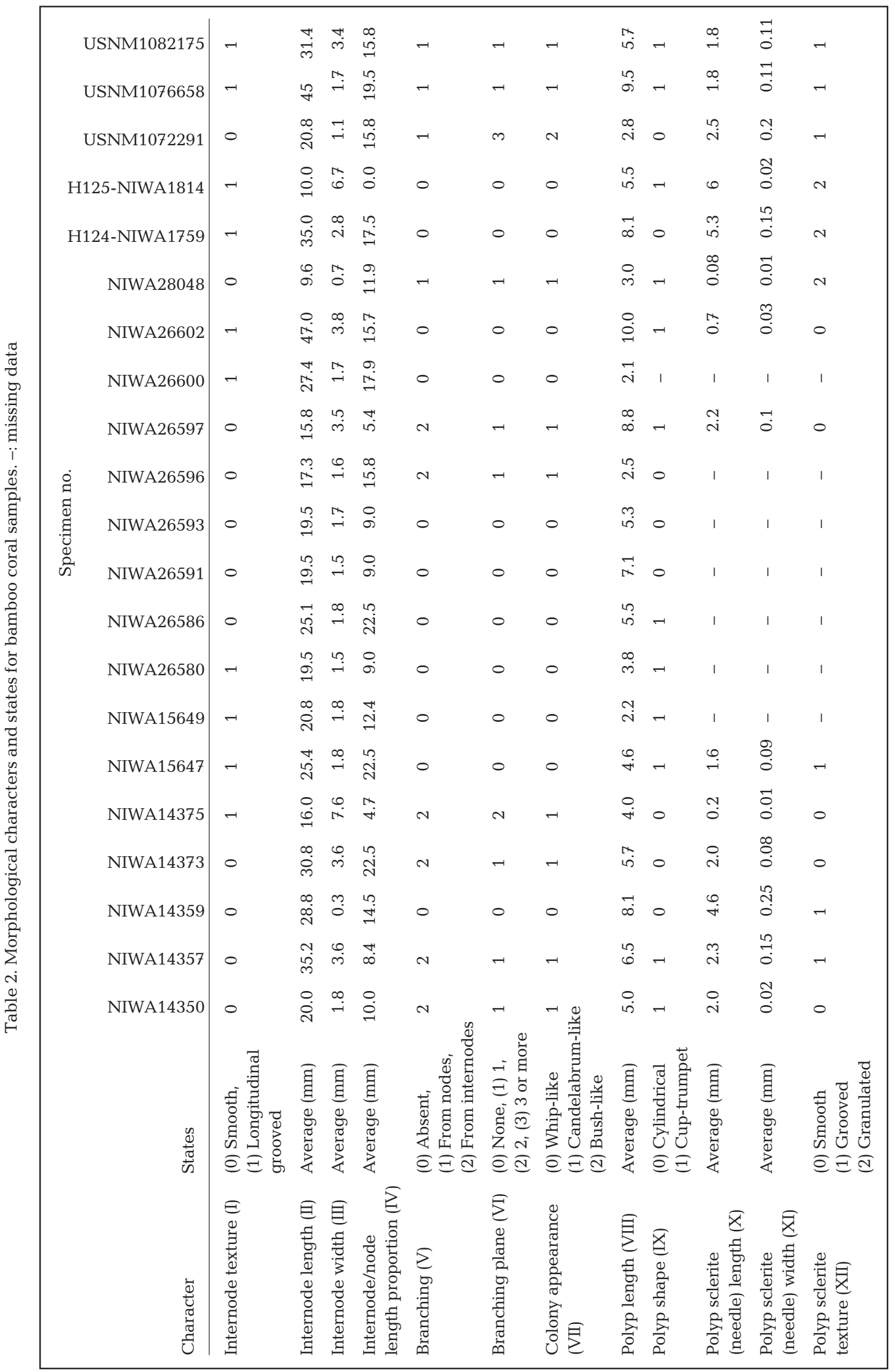




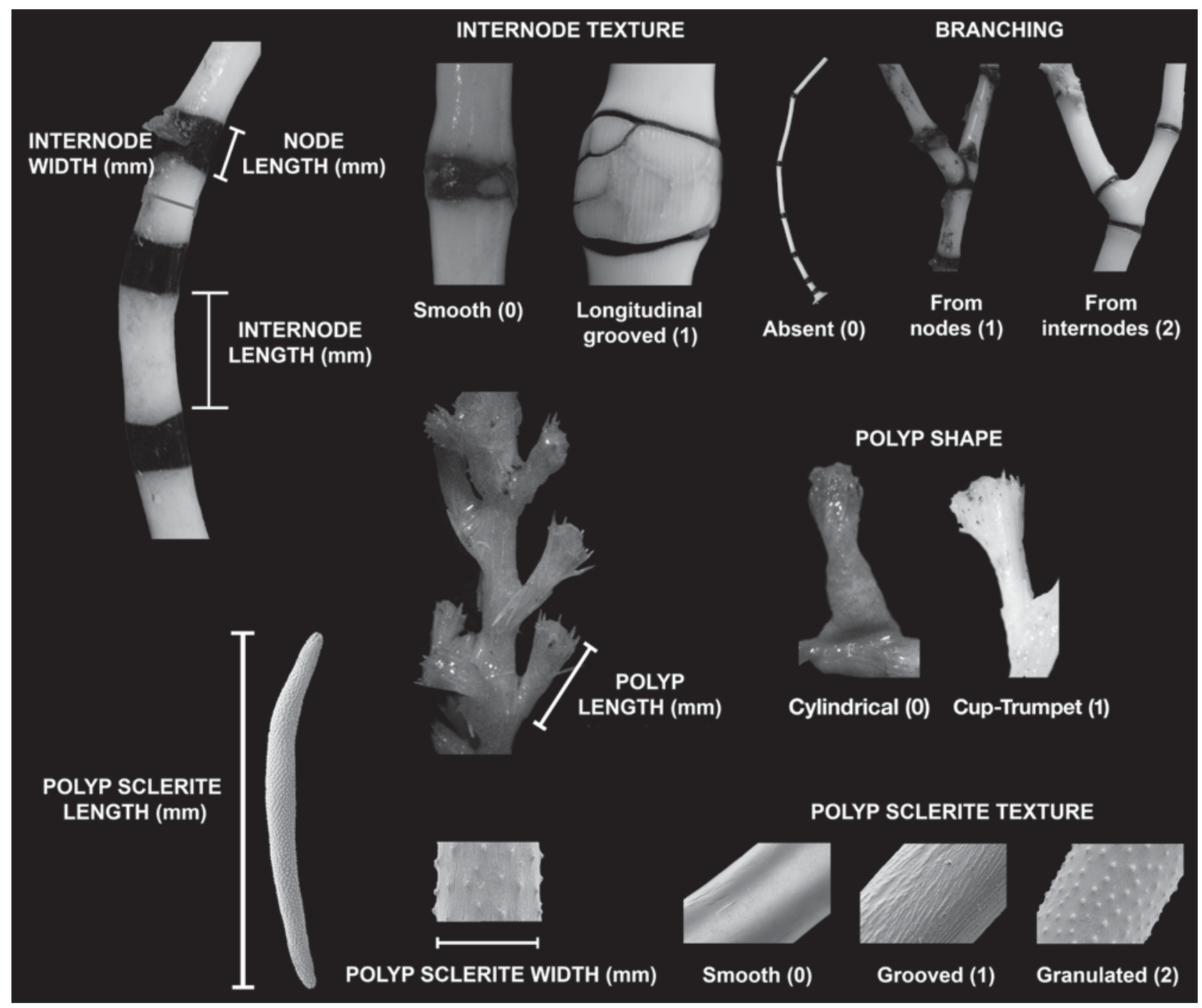

Fig. 1. Some of the morphological characters assessed in the ancestral character state reconstruction (see Table 2)

using the same conditions (Aguilar \& Sánchez 2007). Positive reamplifications were purified and sequenced using the same conditions used for $16 \mathrm{~S}$ mtDNA sequences.

Phylogenetic analysis. One of the many reasons why secondary structures from RNA molecules are useful in systematics is because they are relatively well-conserved structures among eukaryotes (Hunter et al. 2007, Coleman \& van Oppen 2008). Based on the conspicuous homologies, secondary structures facilitate the correct alignment of gene sequences that exhibit a great deal of indels, such as ITS2 (Aguilar \& Sánchez 2007). To improve such alignments, ITS2 and 16S RNA secondary structures were reconstructed for 21 bamboo coral sequences and 1 primnoid (Narella nuttingi for $16 \mathrm{~S}$ and Calyptrophora japonica for ITS2) that was used as an outgroup. The first step was to align the primary sequences (MUSCLE, Edgar 2004) with homologous structures already published, e.g. ITS2 in Aguilar \& Sánchez (2007) and 16S in Sánchez et al. (2003), in order to spot conserved sequence fragments comprising important stem and loop structures. Second, the sequences, along with the restrictions and constraints depicted from the alignment, were submitted in MFOLD (Zuker 2003) with default parameters. From the output files, the skeleton that had the highest negative free energy value and presented essentially the same arrangement as the published structures was chosen.

ITS2 rDNA-predicted secondary structures showed 5 helices around a central ring, as reported for other octocorals (Aguilar \& Sánchez 2007). The most variable sites of ITS2 secondary structures were helices IV and $\mathrm{V}$ (Fig. 2A,B). On the other hand, 16S mtDNA-pre- 


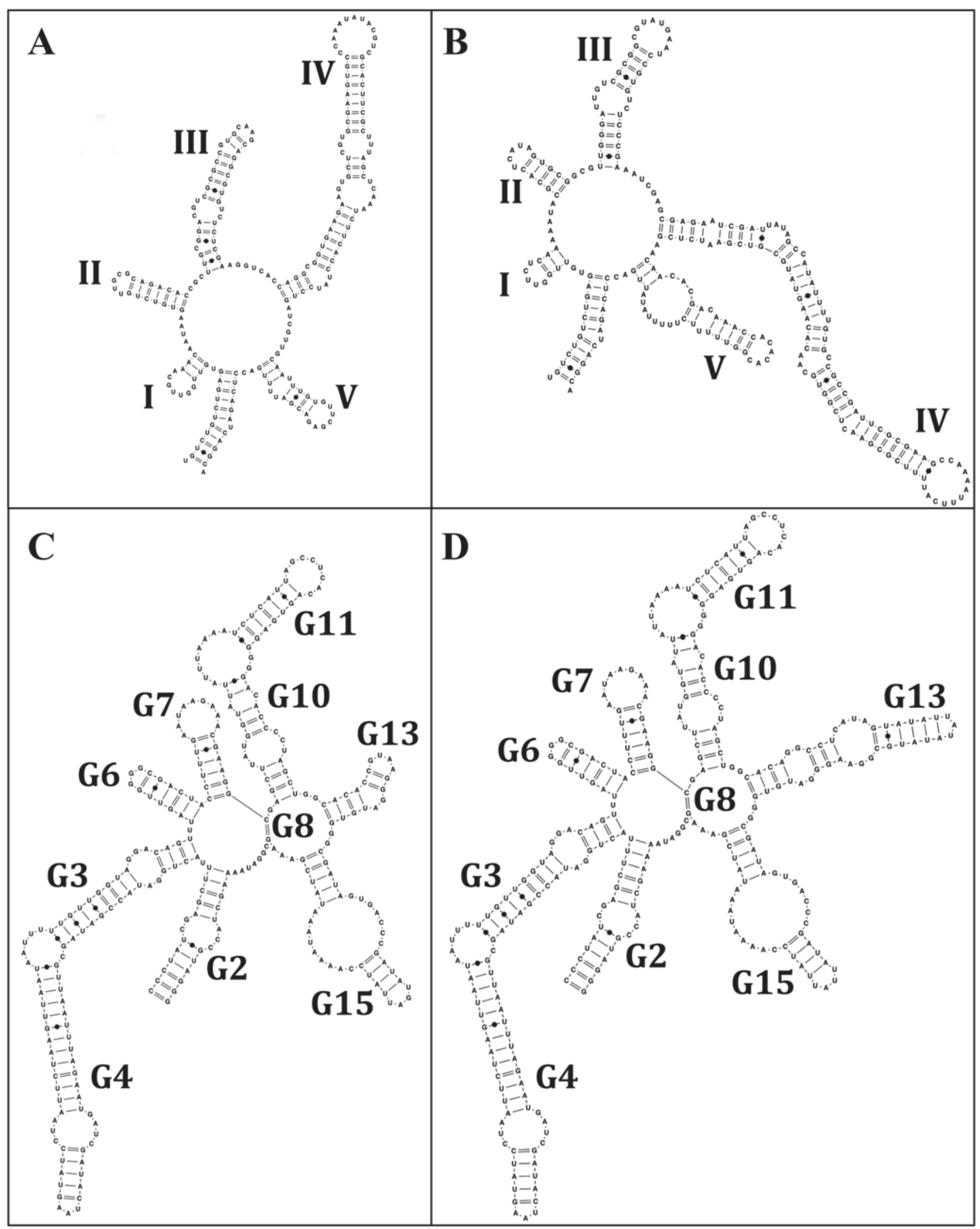

Fig. 2. Examples of bamboo coral (A,B) ITS2 and (C,D) 16S secondary structures. (A,C) 15647 Keratoisis sp. 6. (B,D) S1082175 Isidella tentaculum 
dicted secondary structures presented 7 helices, and were highly conserved among the studied specimens. However, helix G13 was the most variable region (Sánchez et al. 2003, Fig. 2C,D). After obtaining the secondary structures, a new alignment was made with the aid of 4SALE (Seibel et al. 2006). This new alignment took into account not only the primary sequence but also the secondary structure information to make an improved alignment, where homology between sequences was corrected by RNA secondary structures.

Optimal topologies were initially obtained with the maximum parsimony (MP) criterion using PAUP* (Swofford et al. 1996) under the heuristic search algorithm for ITS2 and 16S data sets. A 1000-replicate bootstrap analysis under this criterion was carried out for each data set. For the maximum likelihood (ML) approach, the data sets were uploaded in CIPRES Portal V 1.13 (www.phylo.org) and run using RAxML-VI-HPC v.2.2.1 (Stamatakis et al. 2008) under default parameters with 1000 bootstrap replicates. Finally, Bayesian inference (BI) analyses were made for ITS2 and 16S data sets in MrBayes v.3.1.2 (Huelsenbeck \& Ronquist 2001) with prior settings (settings according to MrModeltest, Nylander 2004, under F81+G substitution model for 16S and GTR+G substitution model for ITS2) and 1 million Markov chain Monte Carlo generations.

Ancestral character state reconstruction. Twelve morphological characters (Table 2, Fig. 1) were chosen to make the ancestral character reconstruction (Ancestral Character State Reconstruction Package) in Mesquite version 2.6 (Maddison \& Maddison 2006) based on the likelihood reconstruction method. Continuous characters were coded in Morphocode (Schols et al. 2004). These characters were mapped on ITS2 and 16S MP topologies that were rooted with the outgroup, which was pruned from the mapping analysis given its lack of morphologic homology.

\section{RESULTS}

\section{Phylogenetic analysis}

From the 21 bamboo coral specimens, 8 had more than one ITS2 copy (e.g. 7 different ITS copies for Kertatoisis sp. 14, NIWA14359). Therefore, we obtained 39 sequences (38 from bamboo coral specimens and 1 primnoid) gathered from the 22 samples (21 bamboo corals and 1 primnoid), and we analyzed a total of 35 ITS2 haplotypes. The ITS2 sequences had variable lengths ranging from 235 to $318 \mathrm{bp}$, and the data set had a total of 519 characters from which 270 were parsimony-informative. Topologies for ITS2 under MP showed 4 well-supported clades (Fig. 3). Clades 2, 3 and 4 were maintained under $\mathrm{ML}$ and $\mathrm{BI}$, but the rela- tionships of the copies within these 3 clades changed (data not shown). Phylogenetic hypotheses showed good branch support in crown nodes based on the 3 methodologies (MP, ML, BI); meanwhile, deeper stem nodes showed better branch support with MP only (Fig. 4). The intra-individual copies were monophyletic for most of the specimens that presented more than one ITS2 copy, except for Keratoisis sp. 6 (K15647), Keratoisis sp. 9 (K26597) and Keratoisis sp. 14 (K14359), where one of their copies (one sequence for each case) was more closely related to other specimens than to its own intra-individual group (Fig. 4). This suggests that in most cases bamboo coral ITS2 presents larger intraindividual than intraspecific variation.

For the mitochondrial 16S phylogeny we used the same 22 samples mentioned above (21 from bamboo corals and 1 primnoid as an outgroup), analyzing a total of 11 haplotypes. The $16 \mathrm{~S}$ sequences had variable lengths ranging from 273 to $313 \mathrm{bp}$, and the data set had a total of 318 characters from which 47 were parsimony-informative. Topologies for 16S under MP showed 4 main clades (Fig. 3). Clades 1 and 2 were maintained under ML and BI. 16S phylogeny showed almost no resolution; just a few of its nodes had high (>91\% for MP and ML or >0.91 posterior probability for BI) branch support (Figs. 3 \& 4). Similar to the ITS2 phylogenetic results, the crown nodes presented better branch support than deeper stem nodes (Fig. 4).

Comparing both topologies (ITS2 and 16S), it was possible to see that relatively few specimens maintained their exact relationship with both genes (Figs. 3 $\& 4$ ). The only clade shared by both ITS2 and 16S topologies was Clade 2, which included K15649 and K28048.

\section{Ancestral character state reconstruction}

None of the selected morphological characters exhibited character states forming monophyletic groups (Fig. 5; see also Supplement 1, Fig. S1 for the other 8 ancestral character reconstructions, available as MEPS Supplementary Material at www.int-res.com/articles/ suppl/m397p011_app.pdf). The different character states appear to have been acquired and lost multiple times.

For the ITS2 phylogeny, only a small number of terminal nodes (Fig. 5A-D left phylogenies) had a 100\% probability of showing a specific character state. Most of the deeper nodes had equivocal states with a $<50 \%$ chance of being one character state or another. On the other hand, the $16 \mathrm{~S}$ phylogeny, with lower resolution and multiple polytomies, offered 11 supported nodes (Fig. 5A-D right phylogenies). For internode texture (character I, Fig. 5A), internode length (character II, 


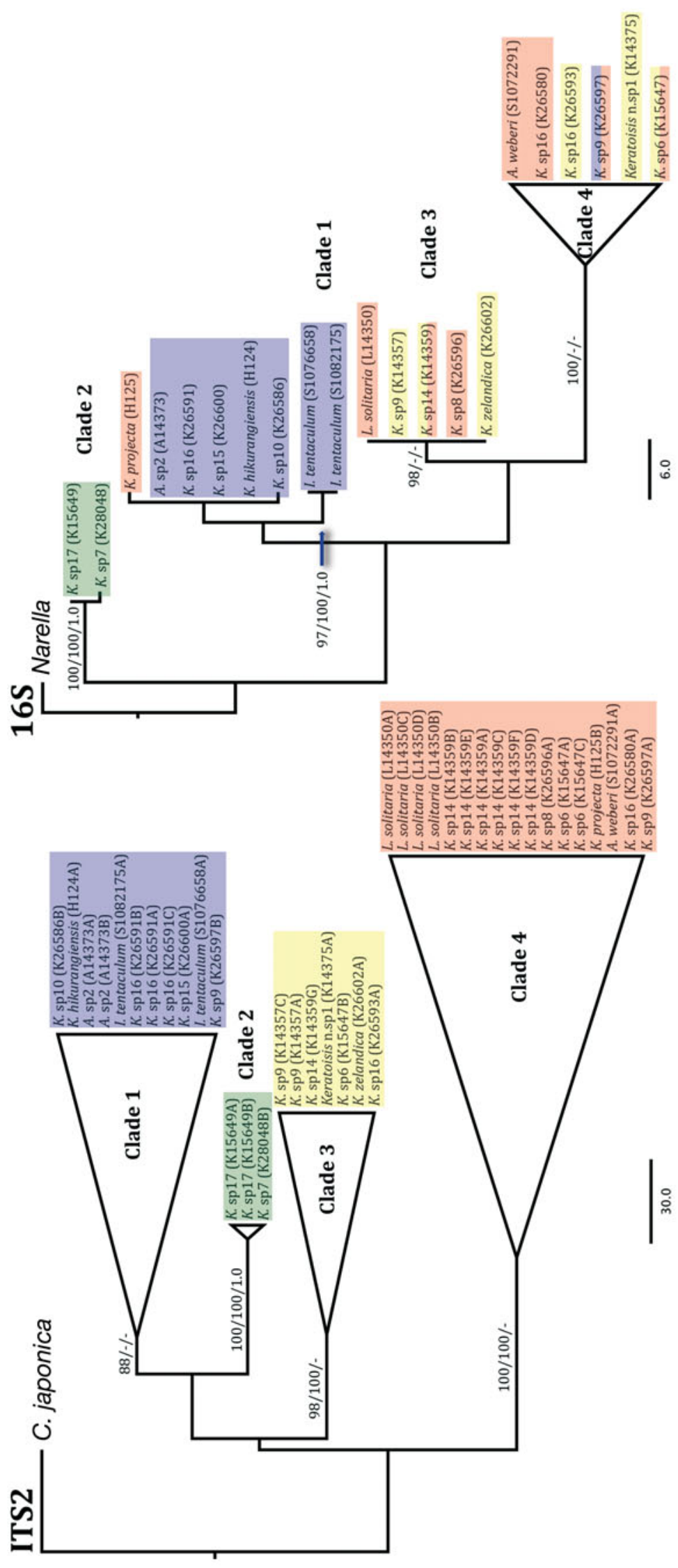

Fig. 5B) and polyp shape (character IX, Fig. 5D), the 11 tree nodes presented exactly the same probabilities. Branching (character V, Fig. 5C), an important feature in bamboo corals, presented very similar probabilities of showing each character state for the 2 deeper nodes.

\section{DISCUSSION}

There were a number of particularities with the ITS2 and 16S phylogenetic outcomes in the present study. Some bamboo coral ITS2 samples presented more than one copy. Multiple ITS2 copies have been reported for other octocorals such as Gorgonia and Pseudopterogorgia (Dorado \& Sánchez 2009). The ITS2 belongs to the ITS region, located within a ribosomal multigene family that could present variations among the repeats (Coleman 2003). The differences in the primary sequences or the repeats could be due to 2 contrasting mechanisms: recent hybridization (Buckler et al. 1997, van Oppen et al. 2001) or incomplete lineage sorting (van Oppen et al. 2001). Further investigation in bamboo coral ITS2 is needed to make robust conclusions on the intragenomic variation and mitonuclear discordance origin.

The phylogenetic topology obtained with $16 \mathrm{~S}$ sequences was poorly resolved. Although this gene has been used to reveal phylogenetic relationships from genus to higher taxonomic levels (McFadden et al. 2006), in this case $16 \mathrm{~S}$ showed little resolution. Low divergent sequences could be explained by the presence of MSH1 mtDNA, a MutS homologue that is putatively in charge of the mtDNA mismatch repair mechanism (Culligan et al. 2000), which has been related to the overall mutation rate in the mitochondria (France \& Hoover 2002). In any case, both ITS2 and 16S molecular phylogenies afforded, but clearly at different levels, a modest phylogenetic signal giving high support values for over 10 internal nodes, which provided 


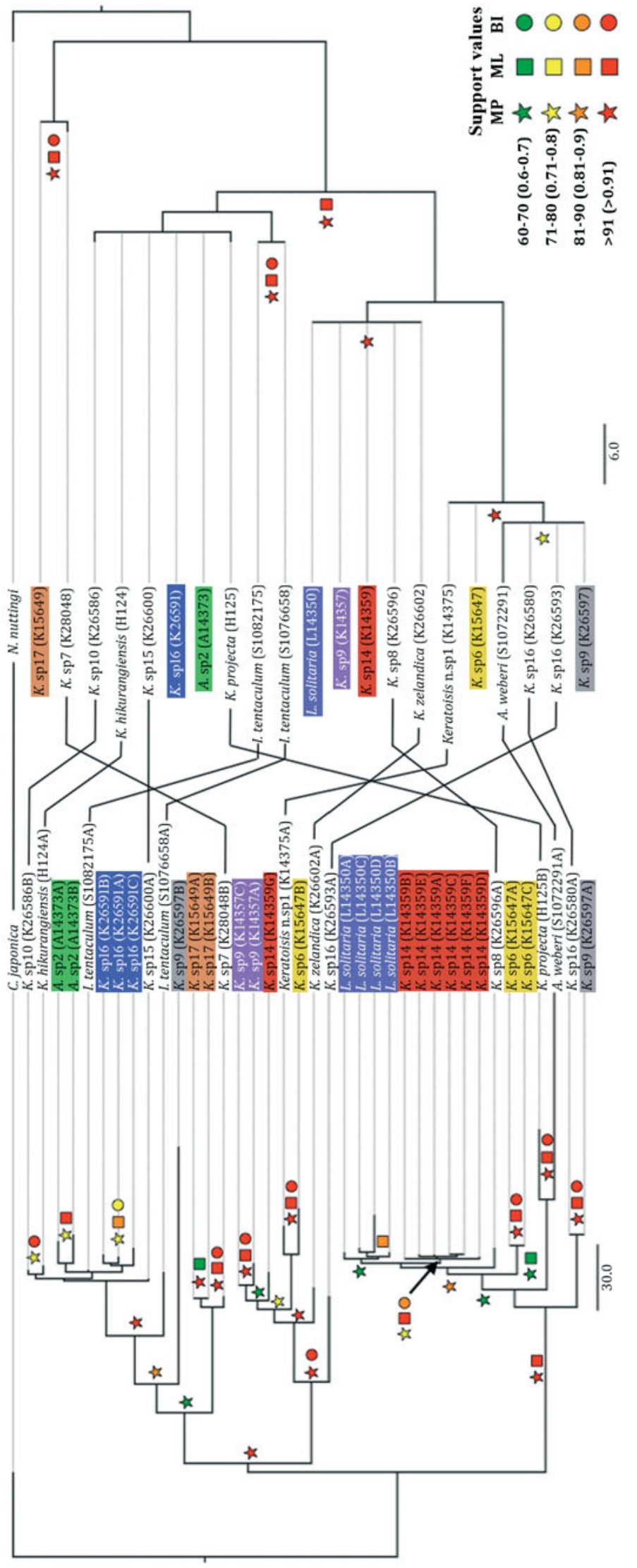

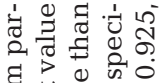

I

द्व

芴

ऽ。

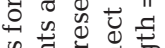

过 혈

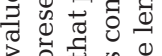

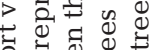

$\pm \Phi$

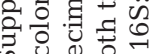

की 0

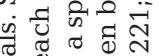

告

$\therefore$ : 8 ब

है क्षे

$\circ$, क

융 훙

द्वे

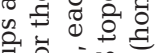

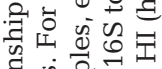

ปै

㐘

. चै $₫$

पू

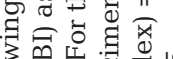

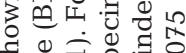

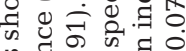

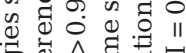

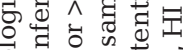

일

융혀웡

$\overrightarrow{0}$ 品学。

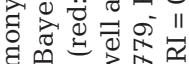

寻

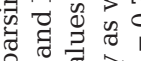

․․

政

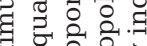

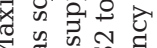

$\sum_{1}^{\infty}$ 的

宊焉

S。

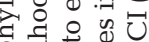

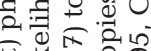

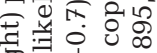

단 0

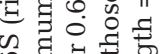

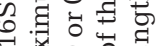

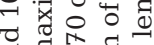

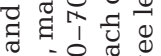

ज证 8

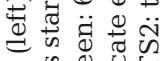

讨

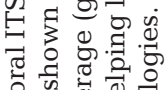

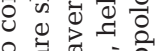

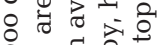

है द्व ठ0

द्वे ${ }^{1} 000$

D.

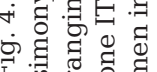

a good phylogenetic scenario for a preliminary assessment of character lability in bamboo corals.

Currently there are no studies that illustrate the systematic relationships (molecular or morphological) of both the Isididae family and its 4 subfamilies (Isidinae, Keratoisidinae, Mopseinae and Circinisidinae). The only study that has provided genetic information to build a phylogeny with keratoisidid bamboo corals is that of France (2007), who used MSH1 sequences from 32 isidids to demonstrate that the distinction between 2 genera (Keratoisis and Lepidisis) should not be established on the basis of branching patterns of the colonies. Other studies, such as Smith et al. (2004), and Brugler \& France (2008), have generated important bamboo coral genetic information, but none have used their findings in a phylogenetic context. Bearing in mind the phylogenetic results of France (2007), it is evident that the MSH1 topology showed no monophyly for the 4 Keratoisidinae genera (Acanella, Isidella, Keratoisis and Lepidisis). This is the same result as that found with ITS2 and 16S phylogenies in the present study. Therefore, based on France (2007) and the data presented here, it is essential to reevaluate the current taxonomy of the Keratoisidinae subfamily.

On the other hand, character lability has been reported for many organisms, with particularly straightforward examples in flowering plants (Kimball \& Crawford 2004), where reproductive characters (e.g. 4 floral and 3 fruit characters) turned out to be polyphyletic. This phenomenon could be due to simple genetic controls. Complexity arising from simple body plans is a typical characteristic in most modular organisms, such as plants and colonial marine invertebrates (Borges 2005). Modular organisms must be capable of adaptive growth, including regeneration of injured parts, due to the high risk of damage imposed by environmental pressures (Hughes 2005). 

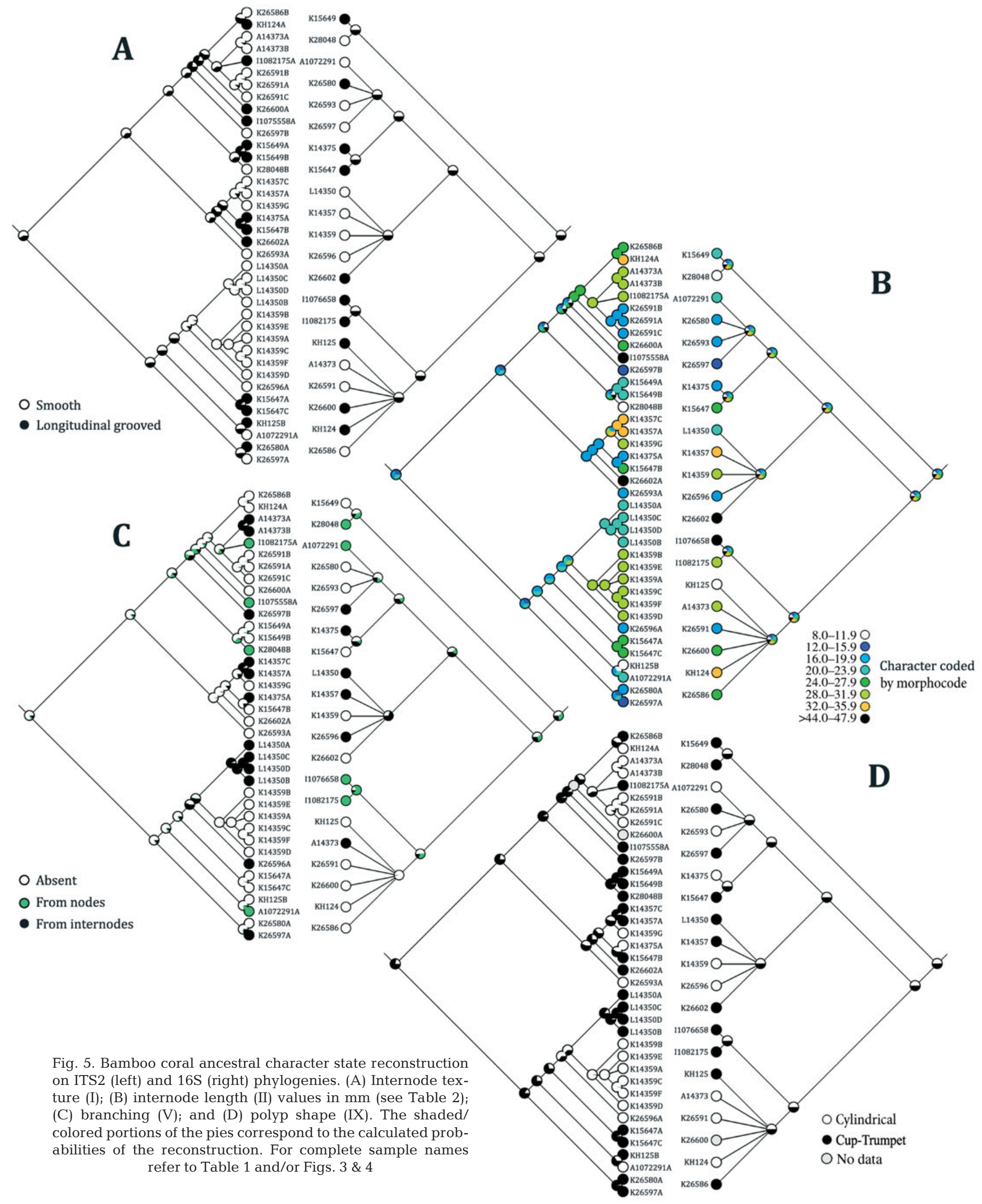
Sánchez \& Lasker (2003) described 2 trait complexes in modular branching octocorals, polyps (modules) and branches (colonial modules), and state that these different levels of integration could respond independently to selective challenges. Therefore, modular organisms such as bamboo corals could have higher character evolvability than unitary organisms.

There was no monophyly on the character states mapped in 16S and ITS2 phylogenies in the present study. They appeared to have been gained and lost several times. A similar result was found by Sánchez (2004) for branching patterns of shallow Caribbean octocorals, where reticulate branching arose 3 different times on the phylogeny. France (2007) also found this same pattern between an MSH1 phylogeny and branching patterns (branched versus unbranched) in some keratoisinid genera. The lack of monophyly shown by the continuous gains and losses of the character states is good evidence for trait lability in bamboo corals.

Would phenotypic plasticity contribute to the observed pattern in bamboo corals? In de Kroon et al. (2005, p. 73) phenotypic plasticity in modular organisms is defined (original definition for plants) as a potentially adaptive response to environmental heterogeneity, not at the individual level, but at the modular level, where the response of the organism 'to its environment is the sum of all modular responses to their local conditions plus all interaction effects that are due to integration'. The phenotypic variation in organisms has been shown to be intra- or interspecific, and this variation overlaps when working with closely related organisms (Meyer \& Paulay 2005), such as bamboo corals. We chose 2 sets of characters normally examined at morphological surveys: (1) meristic characters (one or more distinctive states) and (2) continuous characters (infinite number of states). Character lability can be associated more easily to meristic characters given that their control could be endogenous (i.e. genetic control, Lauter \& Doebley 2002), where little variation over the distinctive states is expected due to environmental pressures. Phenotypic plasticity, on the other hand, may be more associated with continuous characters, giving that they can respond to extrinsic controls such as environmental constraints (de Kroon et al. 2005, Sánchez et al. 2007). This feature may allow the modules to couple or decouple, enhancing the efficiency of resource intake (de Kroon et al. 2005) and the adaptation of the octocorals to different benthic habitats (Sánchez et al. 2007). However, continuous characters can actually be regulated by 3 mechanisms: internal control by the expression of many genes (e.g. quantitative trait loci), external control by environmental constrains or a combination of both (e.g. endogenous and exogenous control). Thus, it would be unwise to say that continuous characters used in the present study are definitely labile. Phenotypic plasticity should be considered as a plausible explanation for the lack of monophyly in continuous characters.

\section{CONCLUSIONS}

Deep-sea bamboo corals show apparently high character lability in multiple morphological characters. This result has a direct repercussion on the group's taxonomic classification, given that characters such as branching or internode texture have been used in the identification of these organisms (Bayer 1990). Therefore, it is necessary both to increase the sampling of bamboo coral specimens and to re-evaluate the current taxonomy of the group. In addition, a next step is to explore the different mechanisms regulating modularity and character evolution in bamboo corals.

Acknowledgements. This study was funded by Facultad de Ciencias, Department of Biological Sciences, Universidad de los Andes (to L.F.D.), the National Institute of Water and Atmospheric Research (NIWA, New Zealand) (to J.A.S.), the Invertebrate Collection at NIWA and The Society of Systematic Biologists with the Graduate Student Award and the Scholarships and Travel Awards for Scientists from Developing Countries (both grants to L.F.D.). The CnidToL NSF-funded project provided partial DNA sequencing (C. McFadden, Harvey Mudd College). We thank many colleagues and friends from NIWA (D. Tracey, K. Schnabel and S. Mills), BIOMMAR (S. Herrera \& N. Ardila), the Smithsonian Institution (S. Cairns) and P. Etnoyer for their generous support and assistance.

\section{LITERATURE CITED}

Aguilar C, Sánchez JA (2007) Phylogenetic hypothesis of gorgoniid octocorals according to ITS2 and their predicted RNA secondary structures. Mol Phylogenet Evol 43: $774-786$

Bayer F (1990) A new isidid octocoral (Anthozoa: Gorgonacea) from New Caledonia, with descriptions of other new species from elsewhere in the Pacific Ocean. Proc Biol Soc Wash 103:205-228

Borchiellini C, Chombard C, Manuel M, Alivon E, Vacelet J, Boury-Esnault N (2004) Molecular phylogeny of Demospongiae: implications for classification and scenarios of character evolution. Mol Phylogenet Evol 32:823-837

> Borges RM (2005) Do plants and animals differ in phenotypic plasticity? J Biosci 30:41-50

> Bousquet J, Strauss SH, Li P (1992) Complete congruence between morphological and rbcl-based molecular phylogenies in birches and related species (Betulaceae). Mol Biol Evol 9:1076-1088

Brugler MR, France SC (2008) The mitochondrial genome of a deep-sea bamboo coral (Cnidaria, Anthozoa, Octocorallia, Isididae): genome structure and putative origins of replication are not conserved among octocorals. J Mol Evol 67: $125-136$ 
Buckler ES, Ippolito A, Holtsford TP (1997) The evolution of ribosomal DNA: divergent paralogues and phylogenetic implications. Genetics 145:821-832

Chippindale PT, Bonett RM, Baldwin AS, Wiens JJ (2004) Phylogenetic evidence for a major reversal of life-history evolution in Plethodontid salamanders. Evolution 58: 2809-2822

Coffroth MA, Lasker HR, Diamond ME, Bruenn JA, Berringham E (1992) DNA fingerprints of a gorgonian coral: a method for detecting clonal structure in a vegetative species. Mar Biol 114:317-325

> Coleman AW (2003) ITS2 is a double-edged tool for eukaryote evolutionary comparisons. Trends Genet 19:370-375

> Coleman AW, van Oppen MJH (2008) Secondary structure of the rRNA ITS2 region reveals key evolutionary patterns in acroporid corals. J Mol Evol 67:389-396

Collin R, Cipriani R (2003) Dollo's law and the re-evolution of shell coiling. Proc R Soc Lond B Biol Sci 270:2551-2555

Collin R, Miglietta MP (2008) Reversing opinions on Dollo's Law. Trends Ecol Evol 23:602-609

- Collin R, Chaparro OR, Winkler F, Véliz D (2007) Molecular phylogenetic and embryological evidence that feeding larvae have been reacquired in a marine gastropod. Biol Bull 212:83-92

Culligan KM, Meyer-Gauen G, Lyons-Weiler J, Hays JB (2000) Evolutionary origin, diversification and specialization of eukaryotic MutS homolog mismatch repair proteins. Nucleic Acids Res 28:463-471

de Kroon H, Huber H, Stuefer JF, van Groenendael JM (2005) A modular concept of phenotypic plasticity in plants. New Phytol 166:73-82

Dorado D, Sánchez JA (2009) Internal transcribed spacer 2 (ITS2) variation in the gorgonian coral Pseudopterogorgia bipinnata in Belize and Panama. Smithson Contrib Mar Sci 38:173-179

Draper I, Hedenäs L, Grimm GW (2007) Molecular and morphological incongruence in European species of Isothecium (Bryophyta). Mol Phylogenet Evol 42:700-716

> Edgar RC (2004) MUSCLE: multiple sequence alignment with high accuracy and high throughput. Nucleic Acids Res 32: 1792-1797

Emerson BC, Gillespie RG (2008) Phylogenetic analysis of community assembly and structure over space and time. Trends Ecol Evol 23:619-630

Etnoyer P, Cairns SD, Sanchez JA, Reed JK and others (2006) Deep-sea coral collection protocols. NOAA Tech Memo NMFS-OPR-28, NOAA, Silver Spring, MD

France SC (2007) Genetic analysis of bamboo corals (Cnidaria: Octocorallia: Isididae): Does lack of colony branching distinguish Lepidisis from Keratoisis? Bull Mar Sci 81:323-333

France SC, Hoover LL (2002) DNA sequences of the mitochondrial COI gene have low levels of divergence among deep-sea octocorals (Cnidaria: Anthozoa). Hydrobiologia 471:149-155

France SC, Rosel PE, Agenbroad JE, Mullineaux LS, Kocher TD (1996) DNA sequence variation of mitochondrial largesubunit rRNA provides support for a two subclass organization of the Anthozoa (Cnidaria). Mol Mar Biol Biotechnol 5:15-28

Geisler JH (2001) New morphological evidence for the phylogeny of Artiodactyla, Cetacea, and Mesonychidae. Am Mus Novit 3344:1-53

Grant R (1976) The marine fauna of New Zealand: Isididae (Octocorallia: Gorgonacea) from New Zealand and the Antarctic. NZ Oceanogr Inst Mem 66

Huelsenbeck JP, Ronquist F (2001) Bayesian inference of phylogenetic trees. Bioinformatics 17:754-755

Hughes RN (2005) Lessons in modularity: the evolutionary ecology of colonial invertebrates. Sci Mar 69:169-179

Hunter R, LaJeunesse TC, Santos SR (2007) Structure and evolution of the rDNA internal transcribed spacer (ITS) region 2 in the symbiotic dinoflagellates (Symbiodinium, Dinophyta). J Phycol 43:120-128

Jousselin E, van Noort S, Greeff JM (2004) Labile male morphology and intraspecific male polymorphism in the Philotrypesis fig wasps. Mol Phylogenet Evol 33:706-718

> Kimball RT, Crawford DJ (2004) Phylogeny of Coreopsideae (Asteraceae) using ITS sequences suggests lability in reproductive characters. Mol Phylogenet Evol 33:127-139

> Lauter N, Doebley J (2002) Genetic variation for phenotypically invariant traits detected in teosinte: implications for the evolution of novel forms. Genetics 160:333-342

Maddison WP, Maddison DR (2006) Mesquite: a modular system for evolutionary analysis, version 26. Available at http://mesquiteproject.org

> Masters JC, Brothers DJ (2002) Lack of congruence between morphological and molecular data in reconstructing the phylogeny of the galagonidae. Am J Phys Anthropol 117: 79-93

McFadden CS, France S, Sánchez JA, Alderslade P (2006) A molecular phylogenetic analysis of the Octocorallia (Cnidaria: Anthozoa) based on mitochondrial proteincoding sequences. Mol Phylogenet Evol 41:513-527

> Meyer CP, Paulay G (2005) DNA barcoding: error rates based on comprehensive sampling. PLoS Biol 3:e422

> Mueller RL, Macey JR, Jaekel M, Wake DB, Boore JL (2004) Morphological homoplasy, life history evolution, and historical biogeography of plethodontid salamanders inferred from complete mitochondrial genomes. Proc Natl Acad Sci USA 101:13820-13825

Noé SU, Dullo WC (2006) Skeletal morphogenesis and growth mode of modern and fossil deep-water isidid gorgonians (Octocorallia) in the West Pacific (New Zealand and Sea of Okhotsk). Coral Reefs 25:303-320

Nylander J (2004) MrModeltest, version 2. Available at www.abc.se/ nylander/mrmodeltest $2 /$ mrmodeltest 2. html

> Ogburn RM, Edwards EJ (2009) Anatomical variation in Cactacea and relatives: trait lability and evolutionary innovation. Am J Bot 96:391-408

Porter ML, Crandall KA (2003) Lost along the way: the significance of evolution in reverse. Trends Ecol Evol 18: $541-547$

> Sánchez JA (2004) Evolution and dynamics of branching colonial form in marine modular cnidarians: gorgonian octocorals. Hydrobiologia 530-531:283-290

Sánchez JA, Lasker HR (2003) Patterns of morphological integration in marine modular organisms: supra-module organization in branching octocoral colonies. Proc R Soc Lond B Biol Sci 270:2039-2044

Sánchez JA, Rowden AA (2006) Octocoral diversity on New Zealand seamounts. Proc 10th Int Coral Reef Symp Japan $5: 1812-1820$

> Sánchez JA, Lasker HR, Taylor DJ (2003) Phylogenetic analyses among octocorals (Cnidaria) according to mitochondrial and nuclear DNA sequences (lsu-rRNA 16S, and ssu-rRNA 18S) support two convergent clades of branching gorgonians. Mol Phylogenet Evol 29:31-42

Sánchez JA, Aguilar C, Dorado D, Manrique N (2007) Phenotypic plasticity and morphological integration in a marine modular invertebrate. BMC Evol Biol 7:122

Sánchez-Villagra M, Williams B (1998) Levels of homoplasy in the evolution of the mammalian skeleton. J Mamm Evol 5: 113-126 
Schols P, Dhondt C, Geuten K, Merckx V, Janssens S, Smets E (2004) MorphoCode: coding quantitative data for phylogenetic analysis. PhyloInformatics 4:1-4

Seibel PN, Müller T, Dandekar T, Schultz J, Wolf M (2006) 4SALE: a tool for synchronous RNA sequence and secondary structure alignment and editing. BMC Bioinformatics 7:498-504

Shaw AJ, Allen B (2000) phylogenetic relationships, morphological incongruence, and geographic speciation in the Fontinalaceae (Bryophyta). Mol Phylogenet Evol 16: 225-237

Silvertown J, Dodd M, Growing D, Lawson C, McConway K (2006) Phylogeny and the hierarchical organization of plant diversity. Ecology 87:39-49

Smith PJ, McVeagh SM, Mingoia JT, France SC (2004) Mitochondrial DNA sequence variation in deep-sea bamboo coral (Keratoisidinae) species in the southwest and northwest Pacific Ocean. Mar Biol 144:253-261

Stamatakis A, Hovver P, Rougemont J (2008) A rapid boot-

Submitted: March 2, 2009; Accepted: September 7, 2009 strap algorithm for the RAxML web-servers. Syst Biol 57: 758-771

Swenson NG, Enquist BJ, Thompson J, Zimmerman JK (2007) The influence of spatial and size scale on phylogenetic relatedness in tropical forest communities. Ecology 88: $1770-1780$

Swofford D, Olsen GJ, Waddell PJ, Hillis DM (1996) Phylogenetic inference. In: Hillis DM, Moritz C, Mable BK (eds) Molecular systematics. Sinauer Associates, Sunderland, MA, p 407-514

> van Oppen MJH, McDonald BJ, Willis B, Miller DJ (2001) The evolutionary history of the coral genus Acropora (Scleractinia, Cnidaria) based on a mitochondrial and a nuclear marker: Reticulation, incomplete lineage sorting, or morphological convergence? Mol Biol Evol 18: 1315-1329

Zuker M (2003) Mfold web server for nucleic acid folding and hybridization prediction. Nucleic Acids Res 31: 3406-3415

Proofs received from author(s): November 20, 2009 